Revista de la red interuniversitaria de estudios sobre las literaturas rioplatenses contemporáneas en Francia

21 | 2020

Glosolalias transplatinas: fantasmas, utopías y ficciones lingüísticas

\title{
Glosolalias: de lo sagrado a lo poético
}

Glossolalies : du sacré au poétique

Glossolalias: From the Sacred to the Poetic

\section{Anne Tomiche}

\section{(2) OpenEdition}

\section{Journals}

Electronic version

URL: http://journals.openedition.org/lirico/9622

DOI: $10.4000 /$ lirico.9622

ISSN: 2262-8339

Publisher

Réseau interuniversitaire d'étude des littératures contemporaines du Río de la Plata

Electronic reference

Anne Tomiche, «Glosolalias: de lo sagrado a lo poético», Cuadernos LIRICO [En línea], 21 | 2020

Publicado el 12 julio 2020, consultado el 29 enero 2021. URL: http://journals.openedition.org/lirico/ 9622 ; DOI: https://doi.org/10.4000/lirico.9622

This text was automatically generated on 29 January 2021.

\section{c) (i) $\Theta($}

Cuadernos LIRICO está distribuido bajo una Licencia Creative Commons Atribución-NoComercialSinDerivar 4.0 Internacional. 


\title{
Glosolalias: de lo sagrado a lo poético
}

\author{
Glossolalies : du sacré au poétique \\ Glossolalias: From the Sacred to the Poetic
}

\section{Anne Tomiche}

1 La glosolalia es un fenómeno que concierne a diferentes campos. El término pertenece inicialmente al vocabulario religioso, en el que designa, según el diccionario Le Petit Robert, un "carisma que se manifiesta por un don de lenguas sobrenatural". A partir del siglo XIX el término designa igualmente, en psiquiatría como en psicopatología, una patología del lenguaje. Más recientemente ingresa al campo de la retórica y de la poética, como lo muestra la presencia de la entrada glossolalie en el diccionario de retórica y de poética Gradus de Bernard Dupriez. De hecho, cierto número de autores contemporáneos, desde las vanguardias de principios de siglo hasta la actualidad, en sus tentativas por liberar la palabra de su referencialidad, se encontraron con la glosolalia. Es el caso, por ejemplo, de André Biely, quien publica en 1922 un poema sonoro cuyo título, "Glossalolija", constituye una clara alusión (Biély 2002). Artaud, por su parte, califica de "cacas glosolálicas" las sílabas inventadas que introduce en sus textos a partir de 1943 (1981: 32). John Barth elige como título "Glossolalia" para uno de sus cuentos de Lost in the Funhouse (1968) y Christian Prigent le da a la farsa satírica que publica en 1996 el título de Glossomanies. Las referencias a la glosolalia son entonces explícitas. Si para Hugo Ball la poesía fonética no está explícitamente asociada a la glosolalia, la descripción de la lectura que hace de su poema "Karawane" en el Cabaret Voltaire en 1916 no deja de ser una evocación del trance místico ${ }^{1}$.

2 Un breve recorrido por la historia de ambas tradiciones (la religiosa y la psicopatológica) ligadas al fenómeno de la glosolalia nos permitirá entender mejor la importancia y las estrategias de tales experimentaciones poéticas, que serán designadas en adelante con el término glosopoiesis para subrayar su dimensión poiética y distinguirlas de las glosolalias religiosas y patológicas. 


\section{Dios y el glosólalo}

3 Cronológicamente la glosolalia es primero un fenómeno religioso, que se perpetúa aún hoy en día en numerosos movimientos carismáticos alrededor del mundo, pero sobre todo en Estados Unidos, donde los movimientos pentecostales se desarrollaron desde principios del siglo XX (se considera que el fenómeno surge por primera vez en 1906 en Los Ángeles, pero la expansión data de los años 50 y 60). Como señala William Samarin en Tongues of Men and Angels (1972), se encuentran pentecostales en iglesias tan diversas como los bautistas, los luteranos, la Iglesia Episcopal Anglicana, los metodistas, la Iglesia de Dios, etc.

4 Las primeras descripciones de glosolalias aparecen en el Nuevo Testamento, aunque el vocablo en sí es un neologismo formado en el siglo XIX a partir de glossa (lengua) y de lalein (hablar), términos que se encuentran de manera recurrente en el Nuevo Testamento, aislados o en diferentes combinaciones. El principal texto en el que se describe el fenómeno del hablar en lenguas es la Primera Epístola de San Pablo a los Corintios: "Pues el que habla en lenguas [lalein glosse] no habla a los hombres, sino a Dios. En realidad, nadie le entiende; dice en espíritu cosas misteriosas"” (Biblia 1999: 1602). Una primera tradición exegética, tan antigua como el comentario de San Juan Crisóstomo, relaciona este texto con el milagro de las lenguas de fuego el día de Pentecostés:

Al llegar el día de Pentecostés, estaban todos reunidos con un mismo objetivo. De repente, vino del cielo un ruido como el de una impetuosa ráfaga de viento, que llenó toda la casa donde se encontraban. Se les aparecieron unas lenguas como de fuego que se repartieron y se posaron sobre cada uno de ellos, se llenaron todos de Espíritu Santo y comenzaron a hablar en diversas lenguas, según el Espíritu les concedía expresarse ${ }^{3}$. (1512)

5 Esta tradición, a la que adhieren los pentecostales, interpreta lalein glosse como el hecho de hablar en diferentes lenguas extranjeras, que no han sido aprendidas. Desde el punto de vista de los pentecostales, no hay diferencia entre el hablar en lenguas de los Hechos y el hablar en lenguas de la Epístola a los Corintios, puesto que se trata de la facultad sobrenatural de expresarse en lenguas humanas sin haberlas aprendido ${ }^{4}$.

6 Si bien Pablo, en su Primera Epístola a los Corintios, coincide con Lucas en los Hechos de los Apóstoles, al considerar que el hablar en lenguas es un lenguaje inspirado por el Espíritu, sugiere sin embargo que se trata de un lenguaje incomprensible para la razón o para el entendimiento humano, mientras que en el relato de Lucas el milagro de los apóstoles hace que sean más fácilmente entendidos. Las palabras del glosólalo no pueden ser comprendidas sino a condición de ser interpretadas: "Si se habla en lenguas, que hablen dos, a lo más tres y por turno; y que haya un intérprete ${ }^{5 "}$ (1604). Precisamente esta cuestión de la inteligibilidad es lo que opone la glosolalia a la profecía, a la gnosis y a toda enseñanza: " $\mathrm{El}$ que habla en lenguas se edifica a sí mismo; el que profetiza, edifica a toda la asamblea. [...] Y ahora hermanos, supongamos que yo vaya a vosotros hablándoos en lenguas, ¿que os aprovecharía yo, si mi palabra no os trajese ni revelación ni ciencia ni profecía ni enseñanza?" (1603). La glosolalia tal y como la presenta Pablo en su Epístola a los Corintios equivale entonces a una plegaria inefable y secreta dirigida a Dios. No se trata de una lengua prebabélica (Pablo no evoca en ningún momento la posibilidad de que se trate de una lengua anterior al hebreo, una lengua que los hombres habrían olvidado), sino de una lengua por fuera de toda lengua 
humana, que solo Dios está en capacidad de entender. Es una lengua radicalmente otra y no simplemente otra porque sería la lengua del otro.

7 Lo que está en juego en la glosolalia religiosa, de las descripciones de San Pablo a las prácticas glosolálicas en los cultos pentecostales contemporáneos, es el fundamento mismo del lenguaje. Fenómeno oral, la glosolalia como fenómeno religioso coincide con el nacimiento del cristianismo. Ahora bien, lo que distingue al cristianismo del judaísmo es la importancia de la oralidad con respecto a la Escritura. Mientras que en el judaísmo todo es escrito, entre los cristianos lo que se transmite no es una Ley escrita, sino una Palabra revelada, el Verbo original de Dios ("En el principio estaba la Palabra y la palabra estaba junto a Dios, y la Palabra era Dios" (1467)). Si, como lo sugiere Giorgo Agamben, "la aparición de una nueva religión coincide siempre con una nueva revelación del lenguaje y una religión nueva significa ante todo una nueva experiencia del lenguaje" (2014: 14), ¿qué vínculo establecer entre la Palabra original divina como experiencia fundamental que instituye al Cristianismo y la glosolalia como palabra carente de sentido?

Una palabra que existe en el principio de los principios debe crear lo que nombra y, por lo tanto, obra a partir de la nada. Tal palabra habla entonces a partir de nada y habla de nada. Como lo apunta Agamben: "la creación a partir de nada no puede querer decir sino esto: la nada por la cual la palabra divina comienza su creación es la nada de la palabra divina misma. Al mismo tiempo que el mundo, la autorrevelación de la palabra postula la nada. La palabra que está absolutamente al principio es una palabra nihilizante (esto quiere decir: la palabra significante debe comenzar por no querer decir nada)" (14).

Lo que se actualiza, una y otra vez, en la experiencia glosolálica, es la experiencia de una palabra que no significa nada, nada salvo ella misma, nada salvo que el lenguaje es. Se abre aquí por ende una dimensión del lenguaje que antecede a todo saber, salvo al saber que hay lenguaje. En este sentido la glosolalia es la experiencia de la pura instancia nihilizante de la palabra en el principio. Aquel que se sitúa exactamente en tal dimensión experimenta el advenimiento mismo del lenguaje, de la instancia del verbo en el principio. La coincidencia "histórica" entre la glosolalia y el nacimiento del cristianismo es una coincidencia onto-teo-lógica, una nueva experiencia del fundamento del lenguaje, entendido como palabra insignificante que funda toda significación.

10 La glosolalia fue entonces inicialmente un fenómeno religioso, y durante mucho tiempo no fue más que eso. En la segunda mitad del siglo XIX -mientras se desarrollaban de manera paralela, por un lado el racionalismo y el positivismo, y por otro lado el ocultismo y el espiritismo- asistimos a un desplazamiento del valor y del significado que se le asigna a la glosolalia. En tanto que se limitaba a ser un modo de comunicación particular con Dios, la glosolalia escapaba a la reprobación de los científicos. Sin embargo, a partir del momento en que pasó del lado del espiritismo (dejando de ser una "plegaria" o un "hablar" divinos para convertirse, por ejemplo, en un discurso proferido desde otro planeta por un muerto), ya no podía seguir siendo ignorada por la ciencia racionalista y positivista del siglo XIX. El argumento esgrimido fue el psicológico. Las revelaciones de San Pablo se convirtieron en enfermedad mental, la glosolalia se volvió patología, una enfermedad orgánica tanto como psicológica. 


\section{El psiquiatra, el lingüista y la médium}

11 El que fuera el objeto de teólogos y de historiadores de la religión -el hablar en lenguas - pasará a ser efectivamente objeto de la medicina y de la psiquiatría, un objeto ligado a la patología del lenguaje. Junto al desarrollo de la ciencia racionalista y positivista del siglo XIX florecieron el ocultismo, el espiritismo y la histeria. Frederica Hauffe, llamada la "vidente de Prevorst" (Prevorst 1900)7 o Élise Muller, más conocida por su seudónimo, Hélène Smith, son apenas dos de esos médiums espiritistas cada vez más numerosos, más o menos histéricos, casi siempre mujeres, que se comunicaban con el más allá en una logorrea glosolálica. Medir el desplazamiento del valor y del significado de la glosolalia, cuando abandona el terreno religioso para entrar en el científico, solo es posible si abordamos la glosolalia como producto del desarrollo del pensamiento racionalista y positivista, y si entendemos la figura de la glosólala como construcción, en una forma invertida, de dos figuras de "eruditos": el médico (psiquiatra en una época en la que el psicoanálisis es incipiente) y el lingüista.

El caso de Élise Muller pasó a la posteridad por el papel que jugó Ferdinand de Saussure pero también porque revela las relaciones entre dos disciplinas emergentes -la lingüística y el psicoanálisis- y el fenómeno de las glosolalias. Médium de la última década del siglo XIX, Élise Muller fue tratada en Ginebra por el ilustre profesor Théodore Flournoy, médico con formación en filosofía y apasionado por la psicología y los fenómenos espiritistas. Entre 1894 y 1901 Flournoy estudió el caso de Élise Muller, asistiendo a sus sesiones de mesas giratorias -en las que intervino- y analizando las transcripciones de las producciones verbales de la joven. En 1900 publica la obra que dará a conocer a su paciente en el mundo entero: Des Indes à la planète Mars. Étude sur un cas de somnambulisme avec glossolalie, el mismo año de la publicación, en Viena, de la Traumdeutung de Freud. El interrogante que suscita el interés de Flournoy es doble, pues se trata no solamente de explicar las causas de las manifestaciones mediúmnicas y de las voces de lugares remotos que oye Élise Muller, sino también de analizar la naturaleza de la lengua que habla la joven. El primer interrogante es de orden psicopatológico y se inscribe en el marco de las investigaciones clínicas de la última década del siglo XIX sobre la histeria y los fenómenos de mediumnidad, que se reflejan en los trabajos de Janet, Charcot, Pfister y Freud. La respuesta que da Flournoy a dicho interrogante es que las voces que escucha Élise Muller y sus visiones son sintomáticas de una disociación de la personalidad. Las alucinaciones auditivas son de origen subconsciente y el sujeto las atribuye a seres diferentes de sí mismo. Desde un punto de vista psicológico, Flournoy explica las producciones glosolálicas de Élise Muller por la potencia autónoma de lo "subliminal" en ella (la "conciencia subliminal" entendida como una suerte de vasta reserva de la que surgiría toda la vida consciente).

13 La originalidad del caso de Élise Muller, con respecto a los otros casos de médiums y de histéricos descritos en ese mismo periodo, radica en el hecho de que sus personalidades inconscientes se manifiestan por la producción de "lenguas" extrañas. De allí se desprende el segundo interrogante de la investigación de Fournoy, de carácter lingüístico. A manera de ejemplo, veamos las primeras palabras que Élise Muller pronunció en "marciano": "mitchma mitchmou minimi tchouanimen mimatchineg masichinof mézavi patelki abrésinad navette naven navette mitchichénid naken chinoutoufiche..." (Flournoy 1983:143). Después del "ciclo" y de la lengua marciana vino el "ciclo hindú" en el que Élise se expresaría en una lengua que asimilaba al sánscrito. 
Si respecto al marciano Flournoy se preguntaba si había que considerarlo como una lengua extranjera, el caso del sánscrito es diferente, puesto que se trata una lengua cuya existencia histórica estaba demostrada, por lo que se trataba de comprobar si efectivamente Élise Muller hablaba o no en sánscrito. Flournoy se dirige entonces al experto entre los expertos en la materia, Ferdinand de Saussure, quien para 1900 no era aún el autor del Cours de linguistique générale pero sí que gozaba de gran renombre como especialista en sánscrito. Desde un punto de vista lingüístico, Flournoy identifica el "marciano" como una forma de francés travestido. Con la ayuda de Saussure, determina que el "sanscritoide" no es más que un simple pastiche, ya que parece sánscrito y contiene incluso fragmentos que tienen cierto sentido, pero el resto resulta ininteligible aunque sin tener nunca un carácter anti-sánscrito.

14 Las producciones de Élise Muller se inscriben en el contexto del nacimiento del psicoanálisis y de la lingüística modernos y para entenderlas hay que tener en cuenta su relación con estas dos disciplinas en proceso de constitución. Mireille Cifali acierta al afirmar que: "su recurso a una lengua -otra, imposible, graciosa, extraña, extranjera, no francesa- constituye uno de los intentos de Élise Muller de rivalizar con el saber positivo del erudito que la observa [...]. Como médium, Mademoiselle es la que sabe, tiene el poder de dar a conocer lo que solo ella escucha y ve" $(239)^{8}$. Lo que se afirma aquí de Hélène Smith puede generalizarse a todos esos médiums del siglo XIX, en su gran mayoría mujeres: "dentro del grupo espiritista las médiums adquieren una posición intelectual, social y religiosa. Habitualmente minorizadas por los hombres decimonónicos, tales mujeres son escuchadas, admiradas, elogiadas, rodeadas. [...] Toman en otra parte lo que en este mundo les resulta vedado y de imposible acceso" (Edelman 1995: 106). El mismo tipo de relaciones transferenciales vinculan a Flournoy con Hélène Smith como a Charcot o a Janet con sus pacientes histéricas o médiums. Hélène Smith es una construcción de Théodore Flournoy tanto como las histéricas fueron una construcción de Charcot o de Janet. Las glosolalias de Hélène Smith son, en varios sentidos, el resultado de la sugestión y de la manipulación, por parte del médico, de las relaciones de transferencia. De hecho, el mismo Flournoy reconoció -aunque sin deducir todas las consecuencias- el papel que jugó en las creaciones de Élise Muller. Por ejemplo con respecto a las pérdidas totales de consciencia, al sonambulismo total seguido de amnesia que Hélène Smith experimentó a partir del momento en el que Flournoy empezó a asistir a sus sesiones de espiritismo, escribe: "temo que tal cambio deba atribuirse en gran parte a mi influencia, puesto que sucedió poco después de mi llegada a las sesiones de Hélène" (30). Mireille Cifali considera que a través de sus intervenciones y de la función que ocupó, Flournoy bloqueó toda posibilidad de evolución hacia algo distinto de la glosolalia.

Hélène Smith no es solamente el producto y la construcción del psiquiatra sino también, y al mismo tiempo, la del lingüista. Como lo subrayó Jean-Jacques Courtine (1988: 91), la glosolalia surge, en esos últimos años del siglo XIX, como la figura complementaria e invertida del lingüista. El programa de la lingüística de Saussure, en gestación durante ese periodo, instaura una división entre la voz y la lengua: "los órganos vocales son tan exteriores a la lengua como los aparatos eléctricos que sirven para transcribir el alfabeto Morse son ajenos a ese alfabeto" (Saussure 1971: 36); el sonido "es tan solo el instrumento del pensamiento y no existe por sí mismo" (24) ; "la cuestión del aparato vocal es secundaria en el problema del lenguaje" (26). En otras palabras, la lingüística de Saussure, lingüística de la lengua, excluye la voz, el sonido, es decir el cuerpo, de su definición del signo. Si el lingüista "descorporiza" la lengua, la 
glosólala, al contrario, "desemantiza" la lengua. El sonido, que no tiene existencia alguna en la lingüística, existe de cierta manera por sí mismo en la glosolalia. La glosólala profiere en un simulacro de lengua lo que el lingüista oblitera en su definición del signo. Lo que nos enseñan entonces las glosólalas espiritistas de finales del siglo es que la glosolalia funciona como el reverso del signo tal y como lo definen los lingüistas que, de Saussure a Victor Henry, se interesaron tanto por dichos fenómenos.

\section{El poeta y la glosolalia}

Las glosolalias, ya sean religiosas o patológicas, suponen entonces a la vez un interrogante sobre su sentido, es decir, sobre la estructura de su enunciado, $y$ sobre su enunciación, es decir sobre el sujeto enunciador. El enunciado glosolálico es un "simulacro de lengua", que se sitúa del lado del sinsentido o del fuera de sentido. La enunciación glosolálica corresponde a una división del sujeto, una alteridad del sujeto para consigo mismo. Ya sea que se trate de la anulación mística del sujeto en la palabra divina o de su división en las alucinaciones auditivas o verbales, es el Otro quien habla en mí. Tal alteridad se enuncia en el sinsentido del enunciado glosolálico, y esta cuestión de la alteridad -tanto a nivel de la enunciación como del enunciado- está en juego en las experimentaciones glosopoiéticas.

17 Si en el glosólalo religioso se reitera la experiencia de un verbo primordial, si en la glosólala espiritista se escenifica el deseo del erudito (psiquiatra, lingüista) de quien es objeto de estudio, en los escritores contemporáneos que han experimentado con el fenómeno de la glosolalia se produce un encuentro con esta doble tradición glosolálica, religiosa y patológica, ya sea que se inscriban en ella o que se distancien.

Khlebnikov y Ball, por ejemplo, se inscriben directamente en la tradición religiosa y mística, en la que el vacío del sentido evidencia una obliteración del sujeto y se convierte en receptáculo de la "plenitud" de la palabra divina. Tanto para uno como para el otro, la voz, una vez vacía de sentido, se "llena" de una trascendencia mística. En el caso de Ball esta dimensión mística de las glosopoiesis es mucho más clara: "El órgano humano representa el alma, la individualidad en su errar entre acompañantes demoníacos. [...] El poema quiere poner de manifiesto [...] el conflicto de la vox humana con un mundo que la amenaza, cautiva y aniquila, cuyo ritmo y ruidoso decurso son inevitables" (2005: 115). La voz se transforma en una especie de entidad psíquica, un alma errante en conflicto con los ruidos del tiempo y de la historia, el lugar de una resistencia interna frente a los asaltos demoníacos del afuera. Allí donde quedaba un espacio vacío de sentido, la voz, que es la huella de ese vacío, se carga de una nueva plenitud: "hemos cargado la palabra con fuerzas y energías que nos permitieron volver a descubrir el concepto evangélico de la 'palabra' (logos) [...]. Intentamos otorgarle al vocablo aislado la plenitud de un conjuro, el ardor de un astro" (133-134). La voz no es entonces más que el lugar que enuncia a un sujeto "vacío", sin consciencia de sí mismo, como lo sugiere Ball al describir su lectura de Karawane:

Las pesadas series vocálicas y el ritmo arrastrado de los elefantes me habían permitido incluso una última subida. Pero ¿cómo iba a rematarlo ahora? Entonces advertí que mi voz, a la que no le quedaba otra vía, adquiría la arcaica cadencia de la lamentación sacerdotal, aquel estilo del canto de la misa, tal y como suena, con aflicción, en las iglesias católicas de Oriente a Occidente. No sé qué fue lo que me sugirió esa música. Pero comencé a cantar mis series vocálicas de forma recitativa al estilo eclesiástico. 
[...] Por un momento me pareció como si en mi máscara cubista apareciera el rostro de un jovencito pálido, azorado, aquel rostro mitad asustado mitad curioso de un muchacho de diez años que, en las misas de difuntos y en los oficios solemnes de la parroquia de su pueblo, está pendiente, tembloroso y ávido, de la boca del sacerdote. (139) precisamente en el momento en que el poeta-sacerdote pierde la posibilidad de decir y de recitar, bajo la forma de una pérdida de consciencia de sus actos ("no sé"). Ya no se trata solamente de una voz, sino de una multitud de voces heredadas, que se propagan de Oriente a Occidente, reuniendo a la comunidad universal de los hombres a través de ese canto sin palabras y por fuera del tiempo. Momento de éxtasis místico y de comunión con los muertos, la "lamentación sacerdotal" conduce, de manera alucinatoria, a la pérdida del yo y de lo real en un espejismo especular en el que el niño entra en comunicación directa, de repente, con el Verbo sagrado. La voz se convierte así en un soplo sagrado, que tiende hacia el grado cero del lenguaje y de la comunicación con los hombres para volverse hacia lo divino y dar a oír "un último recinto santísimo para la poesía". (139)

Igual que en Ball, para Khlebnikov el "juego de la voz fuera de las palabras" (1984: 315), al mismo tiempo que evacúa el sentido y la razón, se recarga con una plenitud que podríamos llamar mística, aunque la redención deba provenir del ser humano, y ya no de un Dios, para dirigirse al ser humano. Muy pronto consciente de la dimensión espiritual de su obra, Khlebnikov escribe a su padre el 5 de junio de 1912: "estoy convencido, y el porvenir lo demostrará, de que podrá usted estar orgulloso de este mantel mágico por mí desplegado y que contiene un festín para la boca espiritual de la humanidad entera" (citado por Jean-Claude Lanne en su introducción a Khlebnikov 1994: 12). El festín, apenas evocado aquí, se asocia explícitamente al milagro de las Bodas de Caná (Evangelio según San Juan 2: 1-10), en "La radio del futuro". En este texto utópico escrito en 1921, Khlebnikov sueña con el gran Todo universal que la radio permitirá construir: "He aquí que aprendemos a transmitir las sensaciones gustativas: a partir de una simple comida, frugal aunque sana, la Radio proyectará el sueño gustativo de sus ondas [...]. La gente beberá agua, pero les parecerá que lo que tienen delante de ellos es vino. Una simple cena se transmutará en suntuoso festín [...]. De esta manera la Radio forjará los eslabones interrumpidos del alma universal y fusionará a la humanidad en un todo único" (Khlebnikov 1970: 218-219). De este festín sagrado, que da acceso al Uno, el zaum hace igualmente parte, porque la lengua transracional "se hace en la boca", para retomar la expresión de los dadaístas, pero sobre todo porque el zaum participa en la vasta utopía del Todo único. La multiplicidad lingüística es el resultado de un olvido de la lengua universal y primordial, la lengua de antes de Babel: "Antiguamente [...] las lenguas [...] unían a los hombres. [...] Ahora, traicionando su pasado, las lenguas sirven la causa de la discordia y, sonidos particularizados para los intercambios de las mercancías de la razón, han dividido a la humanidad multilingüe en facciones de guerra aduanera, en una sucesión de mercados lingüísticos en los que, fuera de los límites de cada mercado, la lengua en cuestión no tiene validez. Cada tipo de moneda sonora aspira a la supremacía y de esta forma las lenguas como tales contribuyen a la desunión de la humanidad y libran guerras quiméricas" (241-242). Por todo ello, Khlebnikov sueña con una lengua única y perfecta, un "nuevo tornado unificador", un "nuevo congregador del género humano" (242): "la lengua transracional es el embrión de la futura lengua universal. Sólo ella puede unir a los 
seres humanos" (Khlebnikov 1986: 91). Verbo sagrado o palabra unificadora, la "voz fuera de las palabras" se convierte entonces, tanto en Khlebnikov como en Ball, en el fundamento de una utopía de lengua universal prebabélica y de comunión sagrada de toda la humanidad.

Si en Ball o en Khlebnikov las glosopoiesis deben abrir el camino, más allá de la desestructuración del sentido, a la plenitud estructurante de una trascendencia, en el caso de otros escritores la dimensión religiosa o patológica de las glosolalias es convocada, pero para ser subvertida a través del humor. Tal estrategia es la que emplea Joyce cuando inserta el caso de la glosólala Hélène Smith en Finnegans Wake, puesto que lo que allí aparece es una "Miss Smith, onamatterpoetic"(1939: 486). El estudio de Flournoy, que empleaba el término "onomatopoioi" para designar a "quienes crean palabras y por extensión onomatopeyas" (269), parece entonces haber influenciado a Joyce, quien transforma "onomatopoioi" en onamatterpoetic, situando lo poético (poetic) bajo el signo de la materia (matter) de las palabras (onoma), una materia que además da a escuchar a la madre (Mutter) como extranjera en la lengua materna.

La ironía y el humor caracterizan también el cuento "Glossolalia" (1988 [1968]) de John Barth, quien juega con el estatus de la interpretación en las glosolalias -religiosas, patológicas y poéticas" 9 . Seis voces diferentes, en seis párrafos distintos, profieren un discurso incomprensible, ya sea porque el sentido del mensaje es oscuro o porque (en el quinto párrafo) la lengua misma es incomprensible. La segunda edición de Lost in the Funhouse (1969) contiene "seven additional author's notes", y en particular una nota sobre "Glossolalia", en la que Barth aporta las "claves" interpretativas identificando las seis voces que hablan: Casandra, Filomena, Crispo -mencionado por Pablo en la Primera Epístola a los Corintios-, la reina de Saba, Alice Le Baron -glosólala que hablaba en "marciano"-, y "el autor". Estos diferentes enunciadores tienen en común, afirma Barth, el hecho de proferir discursos incomprendidos por sus destinatarios. Sostiene además que detrás de esos discursos incomprensibles se esconde una estructura métrica regular e idéntica en las seis estrofas. Marc Chénetier identificó dicha estructura (que es la de la oración que los estudiantes recitaban en las escuelas hasta 1963) y demostró cómo le da al texto una organización que recuerda las experimentaciones del Oulipo (Ouvroir de littérature potentielle), de manera que el texto "incomprensible" revela una estructura y un sentido ocultos (Chénetier 1994: 191-201). La ironía radica en el estatus de la "voz del autor" en el primer párrafo, puesto que la presencia de tal "voz del autor" no solamente sitúa en el mismo plano de incomprensibilidad la profecía, el hablar en lenguas, la glosolalia espiritista y la escritura poética, sino que además crea una tensión entre la incomprensibilidad exhibida y la explicación dada por la "nota del autor" (cuyo objetivo es transformar lo incomprensible en comprensible). Como lo subraya Jean-Jacques Lecercle: "al incluirse a sí mismo en la sexta estrofa de este balbuceo de voces, el narrador confiesa su propia ininteligibilidad y atrapa al lector en una versión de la paradoja del mentiroso: el texto nos dice que es ininteligible, y por lo tanto no podemos haber comprendido lo que hemos comprendido, es decir, que es ininteligible" (1999: 7-8).

Artaud recurre igualmente al humor al jugar con la tradición religiosa y patológica de las glosolalias. Sus glosopoiesis han sido a menudo interpretadas como los delirios de un psicótico místico. De hecho, dichas glosopoiesis surgen en su obra en un período que es a la vez el de su crisis místico-religiosa y de su episodio psicótico. Encontramos registro de ellas, efectivamente, en las primeras cartas escritas en la primavera y el 
otoño de 1943 en el sanatorio de Rodez, cartas con un tono marcadamente místico. En la de marzo de 1943 sobre "L'Hymne aux Daimons" de Ronsard, la glosopoiesis que acompaña al comentario del poema viene a ilustrar la iniciación transcendental que Artaud lee en el poema de Ronsard: "he percibido lo que en ella procedía de Dios y que no puede ser repetido por el hombre más que en la medida en que no haya perdido la comunicación con Dios" (1996: 24). Algunos meses después el mismo Artaud califica la carta destinada a Paulhan, a la que da por título "Kabhar Enis-Kathar Esti", de "texto de comentarios místicos del lenguaje trascendental de los bohemios" (1996: 132). En estos dos ejemplos, las sílabas inventadas se asemejan a fórmulas cabalísticas y pretenden expresar una palabra trascendental. Además, la ficción del libro que Artaud habría "escrito en una lengua que no era el francés pero que todo el mundo podía leer" (1971: 171) refuerza la dimensión mística de una glosopoiesis presentada como lengua universal. ¿Glosolalias de un místico psicótico? Quizás. Aunque cabe subrayar la dimensión negativa del misticismo de Artaud, que lo lleva a identificarse con el Cristo gnóstico del Apocalipsis y que se ve reflejada en el estatus de la figura del Ángel en sus escritos de Rodez y más precisamente en los textos de su denominado periodo místico. En el registro místico estamos lejos, con Artaud, de la positividad y de la plenitud que vemos en Ball o en Khlebnikov.

Ahora bien, las "cacas glosolálicas" no desaparecen ni cuando reniega de la fe cristiana en abril de 1945, ni a su salida del sanatorio en 1946. Por el contrario, Artaud sistematiza su uso. Esto se debe a que subvierte la doble tradición, patológica y religiosa, en la que se enmarca el fenómeno general de la glosolalia y en la que se inscribían en particular sus primeras sílabas inventadas. Artaud no duda en parecer delirante, pero es para hacer escuchar un delirio que es el de la lengua, de una lengua que no es el francés aunque parte del francés: "el canturreo/ escandido, /laico, / no litúrgico,/ no ritual / no griego/ entre negro,/ chino,/ indio / y francés villon [...] Para conseguirlo,/ partir de que soy francés [...]. Seré siempre yo hablando una lengua extranjera con un acento siempre reconocible" (citado por Thévenin 1993: 229). Jugando con la tradición religiosa hasta el punto de trastocarla, Artaud presenta las glosolalias no como la lengua de la Revelación, sino como "caracteres de los que los muy antiguos incunables no fueron más que una imitación [...] diría una transposición [...] encantaciones tontas de falsa jerigonza, apenas buenas para recordar falsos muertos" (1974: 234-235). Las "cacas glosolálicas" no son la lengua revelada por Dios o por el Espíritu Santo, más bien esta última es, irónicamente, la pálida imitación de las primeras. Son, por el contrario, el mejor instrumento "para acabar con el juicio de Dios", y conocemos la importancia dada a los eructos glosopoiéticos minuciosamente consignados por escrito antes de ser recalcados y escandidos oralmente en el programa de radio que Artaud preparó, en 1947, precisamente con el título Pour en finir avec le jugement de Dieu.

Las glosopoiesis, al jugar con la doble tradición religiosa y patológica de la glosolalia, ilustran la existencia de una heterogeneidad radical con respecto a la lengua, de una alteridad constitutiva de la lengua misma. Al dar a oír la voz, el soplo, la pulsión, el cuerpo - todo lo que el lenguaje racional y articulado busca suprimir- las glosopoiesis trazan lo que Deleuze llama "una especie de lengua extranjera que no es otra lengua, ni un dialecto regional redescubierto, sino un hacerse-otro de la lengua, una aminoración de esa lengua mayor, un delirio que se impone" (1993: 15). Alteridades en la lengua, alteridades de la lengua, las glosopoiesis reflejan, en el fondo, una alteridad constitutiva del sujeto enunciador. No tanto porque las alteraciones en la lengua sean el signo de 
una consciencia alterada sino porque después de Rimbaud la subjetividad debe pensarse a la vez como algo desestabilizado y constituido por la alteración y la alteridad, por la relación con lo extraño y con la extrañeza. Las glosopoiesis reflejan entonces una alteridad que es a la vez la de la lengua misma y la del sujeto que la habla y que es hablado por ella.

Tomiche, Anne

"Glossolalie : du sacré au poétique »

Revue de littérature comparé $\mathrm{N}^{\circ} 305,2003$, pp. 61-72.

Traducción de Sebastián García

\section{BIBLIOGRAPHY}

Agamben, Giorgio, "La glosolalia como problema filosófico", Nombres. Revista de filosofía, Universidad Nacional de Córdoba, año XXII, n²8, 2014. Traducción de Franca Maccioni. Artaud, Antonin, CEuvres complètes, vol. IX, Paris, Gallimard, 1971.

---, CEuvres complètes, vol. IX, Paris, Gallimard, 1974.

---, Euvres complètes, vol. XVI, Paris, Gallimard, 1981.

---, Cuvres complètes, vol. X, Paris, Gallimard, 1996.

Ball, Hugo, La huida del tiempo, Barcelona, Acantilado, 2005. Traducción de Roberto Bravo de la Varga.

Barth, John, « Glossolalia », Lost in the Funhouse, New York, Anchor Books, 1988 [1968媐.

Biblia de Jerusalén, Bilbao, Desclée de Brouwer, 1999.

Biély, Andréi, Glossolalie, Paris, Nous, 2002. Traducción al francés de Catherine Prigent.

Deleuze, Gilles, Critique et clinique, Paris, Editions de Minuit, 1993.

Cifali, Mireill, « Une glossolale et ses savants : Élise Muller alias Hélène Smith », La Linguistique fantastique, Sylvain Auroux et al. (ed.), Paris, Denoël, 1985.

Chénetier, Marc, « John Barth : la langue contrainte », Sgraffites, encres et sanguines, Paris, Presses de l'École Normale Supérieure, 1994.

Edelman, Nicole, Voyantes, guérisseuses et visionnaires en France, 1785-1914, Paris, Albin Michel, 1995.

Courtine, Jean-Jacques, « Les silences de la voix », Langages n¹, septembre 1988.

Flournoy, Théodore, Des Indes à la planète Mars. Étude sur un cas de somnambulisme avec glossolalie, prefacio de Marina Yagello y epílogo de Mireille Cifali, Paris, Editions du Seuil, 1983 [1900].

Joyce, James, Finnegans Wake, New York, Penguin Books, 1939.

Kerner, Justinus, La Voyante de Prevorst, Paris, Chamuel, 1900 [1829].

Khlebnikov, Vélimir, Le Pieu du futur, Lausanne, L'Âge d'Homme, 1970. 
---, “La Creación verbal”, Antología poética y estudios críticos, Barcelona, Editorial Laia, 1984.

Traducción de Javier Lentini.

---, Des nombres et des lettres, Lausanne, L'Âge d'Homme, 1986.

---, Nouvelles du Je et du Monde, introducción de Jean-Claude Lanne, Paris, Éditions de l'Imprimerie Nationale, 1994.

Lecercle, Jean-Jacques, Interpretation as Pragmatics, New York, St Martin's Press, 1999.

Samarin, William, Tongues of Men and Angels. The Religious Language of Pentecostalism, New York and London, Macmillan, 1972.

Saussure, Ferdinand, Cours de linguistique générale, Paris, Payot, 1971.

Thévenin, Paul, Antonin Artaud, ce désespéré qui vous parle, Paris, Éditions du Seuil, 1993, p. 229.

\section{NOTES}

1. “...comencé a cantar mis series vocálicas de forma recitativa al estilo eclesiástico [...] y fui bajado de la tarima al escotillón, cubierto de sudor como un obispo mágico”. (Ball 2005 :139).

2. Primera Epístola a los Corintios 14: 2-3.

3. Hechos de los Apóstoles $2: 1-5$.

4. Ver por ejemplo Philippe H. Emerian, L'Art de la glossolalie (Paris, Éd. Le Colombier, 1993) o Donald Hubbard, Le Don des langues. Une approche biblique équilibrée sur un sujet d'actualité controversé (Genève, Paris, La Maison de la Bible, 1996).

5. Primera Epístola a los Corintios 14: 27.

6. Primera Epístola a los Corintios 14 : 4-6.

7. El caso de la "vidente de Prevorst" fue estudiado entre 1826 y 1829 por Justinus Kerner, médico y poeta romántico, que publicó en 1829 La Voyante de Prevorst (reedición París, Chamuel, 1900).

8. [Nota del traductor: salvo que se indique lo contrario en la bibliografía, las traducciones de los textos citados en el original son nuestras.]

9. Ver la lectura que hace de este texto Jean-Jacques Lecercle en Interpretation as Pragmatics, New York, St Martin's Press, 1999, p. 6-14. Lecercle demuestra cómo la ironía del cuento de Barth radica en el hecho de proponer a la vez una teoría de la interpretación 瞖que lo convierte en un

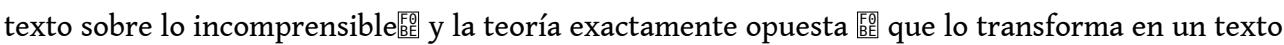
sobre la posibilidad de una comprensión total.

\section{ABSTRACTS}

This article retraces the history of the glossolalic phenomenon. Chronologically, the term glossolalia first referred to a religious phenomenon, which is still present today in a number of charismatic movements throughout the world. Then, in the second half of the XIXth century, the term came to designate a pathological phenomenon. Such a shift in the value and signification of glossolalia occurred at the time of the development of, on the one hand, rationalism and positivism and, on the other hand, occultism and spiritism. The purpose of the present article is to retrace the history of these two traditions (religious and psychopathological) to which 
glossolalia belongs, in order to grasp better the strategies and the stakes of the poetic experiments which, from the early XXth century avant-gardes up to the present, have used glossopoiesis in their attempts to liberate the word from its referentiality.

Fenómeno religioso en sus inicios, presente aún hoy en día en numerosos movimientos carismáticos en todo el mundo, la glosolalia se convierte en un fenómeno patológico en la segunda mitad del siglo XIX. En dicho período -en el que el desarrollo del racionalismo y del positivismo coincide con el del ocultismo y del espiritismo-, asistimos a un desplazamiento del valor y del sentido que le se atribuye a la glosolalia. El presente artículo se propone rastrear brevemente la historia de esa doble tradición, religiosa y psicopatológica, en la que se inscribe el fenómeno de la glosolalia, lo que nos permitirá entender mejor la importancia y las estrategias de las experimentaciones poéticas que, desde las vanguardias de principios de siglo hasta la actualidad, acudieron a la glosolalia en sus tentativas por liberar la palabra de su referencialidad.

Le présent article s'attache à retracer l'histoire du phénomène glossolalique. D'abord phénomène religieux, persistant d'ailleurs encore aujourd'hui dans de nombreux mouvements charismatiques à travers le monde, la glossolalie devient phénomène pathologique dans la deuxième moitié du XIXe siècle. C'est au moment du développement contemporain, d'une part, $\mathrm{du}$ rationalisme et du positivisme et, d'autre part, de l'occultisme et du spiritisme, que l'on assiste à un déplacement de la valeur et de la signification assignées à la glossolalie. C'est en retraçant rapidement l'histoire des deux traditions (l'une religieuse et l'autre psychopathologique) auxquelles se rattachent les glossolalies que l'on peut mieux saisir les enjeux et les stratégies des expérimentations poétiques qui, des avant-gardes du début du siècle jusqu'à aujourd'hui, dans leurs tentatives pour libérer le mot de sa référentialité, ont croisé la glossolalie.

\section{INDEX}

Palabras claves: glosolalia, movimientos carismáticos, patología del lenguaje, experimentación poética, vanguardias

Mots-clés: glossolalie, mouvements charismatiques, pathologie du langage, expérimentation poétique, avant-gardes

Keywords: glossolalia, charismatic mouvements, pathological lenguage, poetic experiments, avant-gardes

\section{AUTHOR}

\section{ANNE TOMICHE}

Université Paris XIII

tomicheanne@gmail.com 